This is an electronic reprint of the original article. This reprint may differ from the original in pagination and typographic detail.

Author(s): Vesisenaho, Mikko; Valtonen, Teemu; Wulff, Anu; Kuittinen, Esko

Title: $\quad$ Using Video Conferencing and Video Recordings for Upper Secondary Distance Teaching: Teachers' View Points

Year: $\quad 2016$

Version:

Please cite the original version:

Vesisenaho, M., Valtonen, T., Wulff, A., \& Kuittinen, E. (2016). Using Video Conferencing and Video Recordings for Upper Secondary Distance Teaching:

Teachers' View Points. In INTED 2016 Proceedings : 10th International Technology, Education and Development Conference (pp. 8582-8589). IATED.

https://doi.org/10.21125/inted.2016.0993

All material supplied via JYX is protected by copyright and other intellectual property rights, and duplication or sale of all or part of any of the repository collections is not permitted, except that material may be duplicated by you for your research use or educational purposes in electronic or print form. You must obtain permission for any other use. Electronic or print copies may not be offered, whether for sale or otherwise to anyone who is not an authorised user. 


\title{
USING VIDEO CONFERENCING AND VIDEO RECORDINGS FOR UPPER SECONDARY DISTANCE TEACHING: TEACHERS' VIEW POINTS
}

\author{
M. Vesisenaho ${ }^{1}$, T. Valtonen ${ }^{2}$, A. Wulff ${ }^{3}$, E. Kuittinen ${ }^{4}$ \\ ${ }^{1}$ University of Jyvaskyla (FINLAND) \\ ${ }^{2}$ University of Eastern Finland (FINLAND) \\ ${ }^{3}$ Kuopio Municipality - Isoverstas network (FINLAND) \\ ${ }^{4}$ University of Helsinki (FINLAND)
}

In Finland the "Isoverstas" (formely ISOverkosto) network of schools coordinates the development of upper secondary distance learning services. The community actually is quite extensive with 65 member schools. In this paper we introduce the results related using synchronous and asynchronous online video resources for distance teaching. The topic is approached broadly at the level of schools and different support services as well as the pedagogical practices of individual teachers. The research data consists of wiki stories written by teachers, the interviews of selected teachers, and an online survey. Data-based content analysis was chosen as the main analysis method with the aim of highlighting the viewpoints offered by the teachers and analyzing them in the light of earlier research results. The ways of using online materials were a resource for independent learning; structured ways of learning including good practices; demonstration material to support teaching in the classroom or online; material for assignments; and flexible sharing materials for web-based courses. In the future the aim is to continue the development work and design new ways to pedagogical practices e.g. using social media software for activating students and increasing collaboration when using the Virtual classroom services. Also, the technical support will be further developed so that support personnel have possibility to administrate teachers' computer online and solve the possible problems for teachers.

Keywords: ICT, pedagogy, distance education, development community, secondary education.

\section{INTRODUCTION}

In Eastern Finland a network of upper secondary schools called Isoverstas coordinates the development of distance learning services for schools. The network has been established in 2004, and over the years the network has expanded to a national community of developers. In the Finnish scale, the community actually is quite extensive with 65 member schools including 59 upper secondary schools and 6 vocational education institutes.

The network offers technical expertise and support during and after installing computer software, webcameras, conference microphones and other required equipment into schools. A video studio software called Wirecast was implemented for video recordings, and for synchronous teaching a flexible application integrating several features was developed. This allowed the teacher e.g. to select the camera view and learning material that will be broadcasted. The webcasts could be recorded and replayed on-demand over the internet.

In addition to technical support Isoverstas provides its members lots of different services like continuous education courses and training for teachers, teaching materials, Moodle learning environment with a selection of free course templates, and a set of tools for distance and other computer assisted teaching.

A specific project Virtual classroom project started in 2010 with funding from the Finnish National Board of Education. The aim of the project was to develop learning environments appropriate for distance learning in upper secondary schools.

In this paper we analyse the Virtual classroom project focusing

- What are the factors affecting the integration and use of synchronous and asynchronous online videos to upper secondary teaching? 


\section{THEORETICAL BACKGROUND}

This section presents earlier research results related to implementation of different technologies and innovations. The topic is approached more broadly at the level of schools and different support services as well as the pedagogical practices of individual teachers.

\subsection{Implementation of Information and Communication Technology}

Implementation of new teaching methods as well as ICT applications is often a challenging process for teachers and schools. Based on earlier research, several factors affecting this process and the success in using different ICT applications can be pointed out. By applying the model illustrating the implementation process of ICT drawn up by Zhao et al. [1], these factors can be roughly divided into three extensive main categories as follows:

First of all, the teachers who start using applications obviously have a central role in the process. Relevant issues arising here are the teachers' knowledge on technology and abilities to utilize ICT. The teacher must be familiar with different ICT applications and the extra work related to their use. When it comes to the role of the teacher, compatibility of the teacher's pedagogical views and the possibilities offered by different technologies is also of great importance. According to Zhao et al. [1], technology is not 'pedagogically neutral', but specific technologies suit better together with some teaching and learning styles than others.

The second factor in the model is the new innovation itself, the used technology and the way of using this technology. This effect is described by using the concepts of distance and dependency. Distance refers to how far the new innovation is from the established practices and approaches of the teacher, the principal and the entire school. Dependency, in turn, refers to the amount of help and support needed from other people to successfully implement the new innovation. A notable distance to the established practices and a great dependency on other people increase the risk of failure when implementing innovations. [1]

The third factor in the model is context. This includes, for example, the support available, i.e. the human infrastructure. A so-called interpreter who understands the goals and needs of the teachers as well as the technical language is also very important. Furthermore, the existing tools and the resources available for acquiring new technologies, i.e. the technical infrastructure, are also brought up as noteworthy factors. The third notable part of the context is social support. Social support refers to the attitudes of colleagues towards the new innovation and the support possibly available from the colleagues.

The characteristics of the teacher constitute the most important factor when implementing new technologies. However, strong peer support and technological support can make the process much easier. [1] Other researchers have compiled similar lists of factors affecting the implementation of different technologies as well. In addition to the same themes, Brinkerhoff [2] draws attention to e.g. the teachers' confidence in their own abilities as well as opportunities to get additional training.

When it comes to the established practices of schools, Pearson and Naylor [3] state that the use of standardized tests has an effect on the implementation of new technologies and innovations. Standardized tests affect the school culture by making the work done in the classroom a case of "surviving the tests", and this in turn can lead to a tendency to avoid risks. Becker [4] discusses the same theme by drawing attention to e.g. the demands set by strict curricula. Standardized tests and strictly defined curricula can lead to avoidance of risks, thereby discouraging the use of new methods and technologies.

In relation to the pedagogical views of teachers referred to [1], Ertmer [5,6] discusses the pedagogical beliefs of teachers. Ertmer $[5,6]$ differentiates between different styles of utilizing ICT in teaching by dividing them into two categories: high-level and low-level utilization. By low-level utilization of technology Ertmer refers to teacher-centered models whereas high-level utilization refers to more student-centered models based on constructivism. Implementation of high-level methods emphasizing the more active role of students should be set as the goal in modern school environments.

\subsection{Pedagogical viewpoints}

There are different pedagogical emphases when it comes to utilizing ICT in teaching. Zhao et al. [1] draw attention to the pedagogical practices related to different technology applications for teaching and learning. The underlying assumption is that no such pedagogically neutral teaching technology 
exists where the technology itself would largely define the pedagogical methods used in a classroom setting. Niederhauser and Stoddard [7] offer an alternative view by stating that the pedagogical practices depend on the teacher. The reason for these conflicting views may be confusion over which applications are seen as 'teaching technology': does the application have to be designed specifically for some predetermined contents and methods, or does e.g. Microsoft Word count as teaching technology? This article follows viewpoint on placing importance on the way in which technology is used, not on technology itself [8-11].

When discussing the pedagogical beliefs of teachers, Ertmer $[5,6]$ divided the styles of using different technologies into teacher-centered models and student-centered models based on constructivism. There are several similar divisions based on behaviorism and constructivism offering different viewpoints on the issue. Kember [12] as well as Kember and Kwan [13] described teachers' views on teaching by means of a five-step continuum ranging from a view of teaching as imparting information to a view of teaching as conceptual change / intellectual development. The trajectory of teaching technologies has proceeded from models based on data transfer and continual repetition towards more communal methods in a similar fashion [9]. The active role of the student, interaction and collaborative construction of knowledge are emphasized in the communal models. When it comes to the role of ICT, possibilities for interaction, highlighting different viewpoints, collaborative content production and making the learning process transparent are of great importance.

In this study, the use of virtual classroom services is discussed by applying the aforementioned themes and also acknowledging the grey area between the extremes. A model developed in the Wang et al. [14] is utilized in the study. The model draws attention to the technical possibilities of environments similar to the virtual classroom services (Fig. 1). Central aspects of the model include the emphasis on the roles of the teacher and the students as well as the use of video, sound or other communication tools either simultaneously (synchronously) or as recordings (asynchronously)]. This basis constitutes a framework for categorizing the usage styles of virtual classroom services in this study.

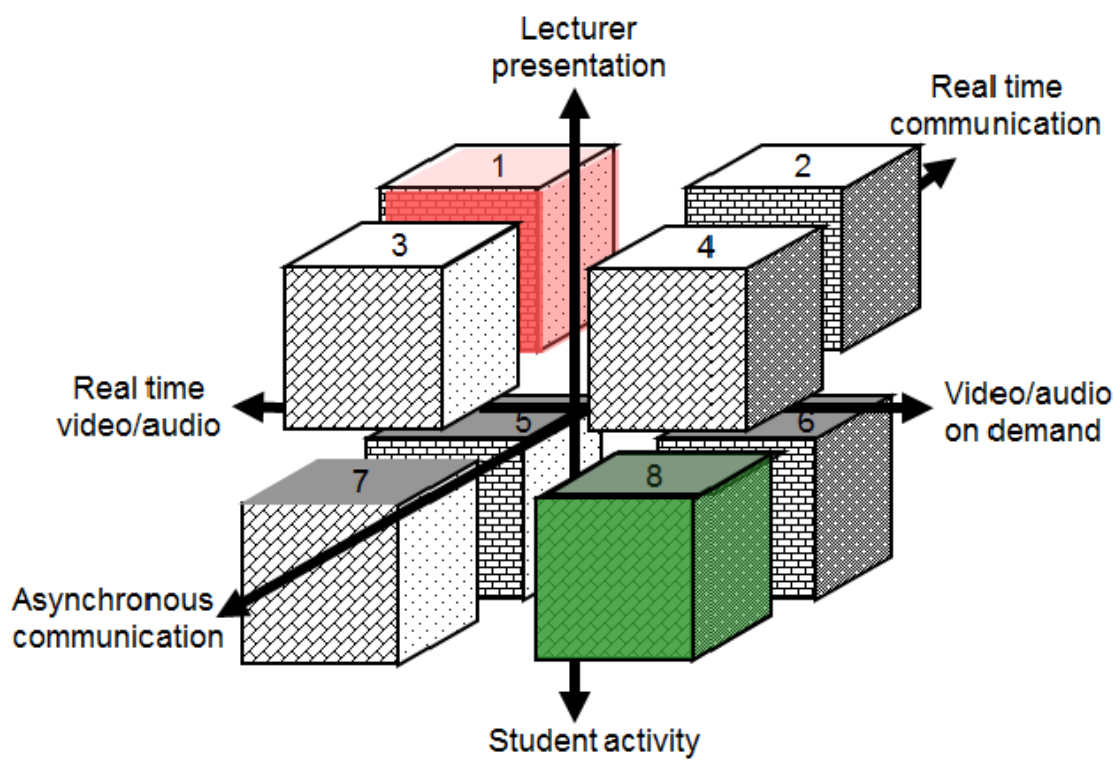

Figure 1. The roles of a teacher and a student and the use of communication tools simultaneously or asynchronously [14]

\section{RESEARCH PROCESS AND ANALYSIS}

This research concentrates on the experiences acquired during the implementation phase as well as the pedagogical viewpoints and the ways of using the services. The primary data consists of wiki stories written by teachers $(n=21)$ who participated in a long-term educator training (four days of training and individual work between training sessions) organized by the virtual classroom project in 2010. In these wiki stories, the teachers reflect on their experiences of the virtual classroom project. Furthermore, the interviews of seven teachers and the results of an online survey were used as research data. The interviewees were selected on the basis of the wiki stories, and the interviews 
were carried out in spring 2011 as five separate interviews conducted either individually or in pairs. The online survey was carried out in spring 2011. The survey was directed the teachers $(n=68)$ of the upper secondary schools participating in the project, the support persons of the project $(n=35)$, students $(n=186)$ and principals $(n=32)$. However, the sample of the online survey remained relatively limited, and therefore the results are only indicative supporting the qualitative data by offering additional viewpoints.

Data-based content analysis [15] was chosen as the analysis method with the aim of highlighting the viewpoints offered by the teachers and analyzing them in the light of earlier research results. The analysis proceeded through different stages. At the first stage, the texts, wiki stories and interviews were read through several times with the goal of gaining a general impression of the themes arising from the data. At the second stage, the analysis was continued by using the Atlas.Ti application for initial coding of the data and dividing the data into different segments. The size of different analysis units varied from one sentence to an entire paragraph. At the third stage, the themes acquired as the result of the initial coding were combined to create bigger entities. These entities represent the contents of the result section where the results are compared with the earlier research results introduced in the theory section of this article.

\section{RESULTS}

\subsection{Factors affecting the use of Virtual classroom}

Results from the survey indicate that Virtual classroom and its applications (later Virtual classroom) were still used only by minority of teachers in the schools. The mean value for the statement" Only minority of teachers use Virtual classroom actively (scale $1=$ Totally disagree, $5=$ Totally agree) was high $4.43(n=68)$ indicating that the integration of the Virtual classroom was still in progress i.e. currently used only by a limited amount of teachers. Also, the mean value for the statement "Students demand active use of Virtual classroom from teachers" was only $1.68(n=68)$ indicating that either students did not know about the possibilities of Virtual classroom or did not find services useful for their learning. The following paragraphs outline factors affecting the integration of the Virtual classroom. The following themes are based on qualitative data from open questions, wiki-stories and interviews.

First theme concerns teachers' motivational aspects. Results indicate different opinions for learning the Virtual classroom system and starting to actively use it. Perceptions varied, at the positive side teachers' indicated personal interest towards new system i.e. teachers saw the Virtual classroom as a new and interesting possibility for develop their work and learning environments. At the other end teachers felt that they are forced to use Virtual classroom, taking advantage of the new system was perceived as a demanding process demanding extra work. Some comments even indicated fear toward the new system.

"we have a really small work community, almost everyone wants to learn how to use Virtual classroom and (last time today) I have helped my colleagues how to create recordings"

"some teachers are very pleased with the new system, some teachers are afraid of and doesn't even want to try"

"We would rather continue fruitful face-to-face teaching. The pressure from the principal doesn't increase the willingness to use Virtual classroom"

Perspective for using (or not) Virtual classroom outlined also more practical aspects related to teachers' work. First, for some teachers teaching and learning online and utilizing the Virtual classroom was seen as vital for their school. Many of the participating schools are small; they have to survive with lowering number of students. For this challenge Virtual classroom provide new opportunity for building collaboration with other schools. On the more negative site teachers brought up the question of salary. Using video recordings demand new kind of agreements about the license to use them and payments. Another practical aspect preventing the use of Virtual classroom was the lack of resources. In most schools there were only one or two classrooms equipped with Virtual classroom services. This caused demand for organizing the use of limited resources.

"I have a rather positive opinions toward the Virtual classroom because it is almost a obligatory for the surviving of our small school. " 
"The use of Virtual classroom is obligatory, without the Virtual classroom and possibilities for collaboration between schools teaching of some subjects would have ended because of the small number of students."

"The negative side is the big amount of extra work that teachers have to do without extra salary ... some teachers are afraid of their salary."

Results also indicate that the role of the schools' principal is important. In best cases the principals' interest and positive attitude toward the new Virtual classroom had a strong positive impact for integrating the Virtual classroom for schools' everyday work. On the contrary the principal's negative and underestimating attitude toward the Virtual classroom can hinder the use of Virtual classroom.

"I think it all started because our principal was excited about the Virtual classroom, or this is how I feel it, he had this new idea of recording the classes. Then I started to try the new possibilities myself... so that I think it was all because of our principle."

"Our new principal doesn't really appreciate the Virtual classroom, making recordings. And actually I don't make recordings any more..."

One important factor affecting the use of Virtual classroom was technical challenges related to new technology. An important aspect for overcoming these challenges was the support service provided by the Isoverstas network. Teachers were able to call for support and gain support and advices just when needed. At the beginning new technologies caused even overly cautious behavior because of the afraid of breaking new technologies or making mistakes. Still, with experience teachers' became more skilled and more willing to find solutions for technical problems by themselves.

"Right time support is necessary because problems need to be solved fast during classes"

"The classroom with Virtual classroom became a sort of a sanctuary, the main advice for teachers was "don't' touch anything, bypass the wires as far as you can"

"Eventually I learned to solve problems myself which was very rewarding"

\subsection{Video recordings as learning resources}

Flexibility is a key way to apply asynchronous recordings (8 persons mentioning). From the student point of view it offers opportunity for study independently when one cannot participate the face-to-face lesson. Especially the adult students and athletes see the value and take advantage of this opportunity. When concurrent lessons students apply this opportunity.

"Students applied the recordings while they had been were ill"

"The persons benefited were adults students, athletes etc."

The recordings offer also flexibility for the teachers as the students are also video or audio producers; especially the language teachers see the value of this. The wiki data also gives examples of storing students' products as the students have been encouraged to be active designers and producers of the video materials.

Some teachers also have been deputizing for themselves by using recorded lessons when participating e.g. continuous education.

"The recordings were teaching while I was participating continuous education..."

Next category was for key issues of the course and recapitulating (12). These are most often short video vodcast like 5-10 minutes video recordings on a certain key topic of the course emphasizing the challenging themes. These were used independently, but also as a part of the organized activities of a whole online course. The videos were also used for comparing own solutions of the home works to a video example of how the exercise should be solved.

"eBeam and touch screen integrated to system were the main ways I applied and recordings of those in math"

"Short info recordings 5-10 minutes for the students were applied"

Practical examples can be well visualized by recordings (5). These are applied especially when learning practical skills and doing demonstrations e.g. in physics and chemistry (offering also 
opportunity to apply visualization and demonstration software simultaneously). A benefit of visualization was to concretize and add new layers to understanding.

\subsection{Synchronous distance teaching}

Virtual classroom provides different ways for supporting teaching and learning. Recordings were designed to provide students with more flexible learning possibilities, as a new type of learning material that can be used when needed even by students themselves or by guidance of the teacher. Virtual classroom for simultaneous distance teaching was typically used for teaching students in different schools, typically optional courses with small number of students in each school.

The views on simultaneous distance teaching varied. Challenges with Virtual classroom were typically on distance teaching concerning quite practical issues such as how to enhance the quality of voice and picture i.e. quality of collaboration. Teachers tried out different ways to overcome the challenges for example by using headsets-microphones and with additional cameras. Also, in order to better familiarize themselves with the students some teachers decided to teach classes in turns from all participating schools so that they can actually meet all the students. Virtual classroom limited some teachers pedagogically: the area cameras covered in the classroom was seen too small and restricting their teaching work. A group of teachers used to lecturing type of teaching this was not a problem rather it was seen as a suitable feature for their work.

"Next year I will visit on different participating schools and teach from those schools in order to make the acquaintance with all students..."

"During the classes I typically move a lot, wave my hands etc. so for me it was a bit like a cage bird, I had to stay in one place in order to better acknowledge the distance students"

"I think the Virtual classroom is really suitable for me, I prefer lecturing type of teaching... I think my classes would be pretty much the same even without the Virtual classroom."

Teachers also indicated that the use of Virtual classroom demand more defined pre-planning of the classes. More detailed planning can be seen in designing the learning materials and also in more detailed scheduling of the classes.

"Classes need to be planned better and in more detail, you have to pay attention to the way how you speak, what kind of materials you are using i.e. how they shows for distance students or in the recording, If you use different medias you will feel a bit like movie director."

In addition to Virtual classroom different online services were mentioned as a way to support the teaching and learning with Virtual classroom. Recordings were added as a part of online courses, also different social media software applications like Facebook were mentioned as a way to share the recordings and as a way to add collaboration. The role of social software is one of the areas that will be further developed. Social media software provides a variety of ways to increase especially the collaboration between students.

\section{CONCLUSION}

The integration of Virtual classroom to schools has proceeded rather well, still more integration and development work is needed. Results outline several factors affecting integration process. Compared to results by Zhao et al. [1] the factors were related to the school culture, support available and technical possibilities and challenges.

According to Zhao et al. [1] integration of new innovation will be successful if the new innovation is not, too far from the earlier practices. Based on the results of this study we can assume that the new practices with Virtual classroom i.e. distance teaching and classroom recordings are close to schools' earlier practices. Especially with recording the changes are small. Changes indicated were mainly about more detailed planning of classes and higher quality learning materials. Also the schools participating to research had a long history of the Isoverstas network indicating that teachers had already experiences of distance teaching and learning. Still, even though the new practices were close to earlier practices the role of principal seemed important. Inspiring and encouraging principal can have a strong effect on integrating new technologies and teaching and learning practices into schools' everyday practices. On the other hand, principle with negative attitude and especially with technical difficulties will hinder the integration and cut out the use of new systems. 
Zhao et al. [1] argues also that colleagues and support available are vital for integrating new technologies. These topics also could be seen in the results of this study. The support for installing new technologies and especially the 'just-in-time' support was seen important. Typically the problems with technology appear just before the classes begin or during classes, in these situations the support available via phone or other 'just-in-time' application is vital. Zhao et al. [1] also indicate the role of teachers' personal skills to use new technologies. In this case teachers also got in-service training. The training offered teachers new ideas on how to take advantage of the Virtual classroom and especially provided possibilities for collaboration between colleagues to change ideas and experiences.

According to Ertmer [6] teachers' pedagogical beliefs and possibilities provided by new technologies has effect on the integration process. Virtual classroom was experienced both as suitable for teachers' pedagogical practices but also as restring factor of teaching practices. Virtual classroom was seen as suitable for teacher led lecturing; still for some teachers it was limiting their pedagogy. Meeting some of the students only virtually was a challenge for teachers. This problem was avoided when teacher was teaching from all the schools participating, one after another. Zhao et al. [1] referred to pedagogical limits that different technologies set for teaching practices. Based on the results of this study these limits can be questioned and emphasize teachers' innovative and creative role in teaching with technology. Results align with arguments by Lehtinen [9] who suggest that the most important aspect when teaching with technology are the pedagogical solutions, not the technology itself.

Compared to pedagogical cube [14] described in Fig. 1 the use of Virtual classroom mainly utilized in asynchronous classroom recordings and synchronous distance teaching. Recordings were typically whole lessons or shorter moments. Typically the recordings were provided for students as a possibility for more flexible learning, especially for more self-directed learning and for rehearsing. The use of recordings were relying on students own activity. In addition, there were also recordings designed as learning assignments where teachers had also the role of tutor with more interactive elements (synchronous / asynchronous). Also, recordings were used during classes as a way to better illustrate different phenomena. When comparing these ways to the conceptions of teaching by Kember [12] we can see that the use of recordings emphasize teacher centered practices. Student centered ways and students active role shows mainly in ways of tutoring the use of recordings. In the Virtual classroom was used for synchronous distance teaching that align with cube models streaming of video and voice. The aim was to provide students lessons in certain subjects, which they had not been able study otherwise in their small schools. Distance teaching was mainly teacher led lecturing and students working two by two emphasizing more collaborative practices.

Since the beginning of the use of Virtual classroom different practices and ways of using the service have developed, and many of them are already utilized. In the future the aim is to continue the development work and design new pedagogical practices. Teachers already suggested and are using for example the social media software for activating students and increasing collaboration when using the Virtual classroom. Also, with additional cameras and screens have been installed to have more classroom like environment in distance as well. In this way teachers have more possibilities to see how different students are working and are able to provide more personal guidance. Also, the technical support is and will be further developed to have better online possibilities to administrate teachers' computer and solve the possible problems for teachers. 


\section{REFERENCES [Arial, 12-point, bold, left alignment]}

[1] Zhao, Y., Pugh, K., Sheldon, S. \& Bryers, J. (2002). Conditions for classroom technology innovations. Teachers College Record, 104(3), pp. 482-515.

[2] Brinkerhoff, J. (2006). Effects of a long-duration, professional development academy on technology skills, computer self-efficacy, and technology integration beliefs and practices. Journal of Research on Computing in Education, 39(1), pp. 22-43.

[3] Pearson, M. \& Naylor, S. (2006). Changing contexts: Teacher professional development and ICT pedagogy. Education and Information Technologies, 11(3-4), pp. 283-291.

[4] Becker, H. (2000). Findings from the teaching, learning, and computing survey: Is Larry Cuban right? Center for Research on Information Technology and Organizations.

DOI=http://www.crito.uci.edu/tlc/findings/ccsso.pdf

[5] Ertmer, P. (1999). Addressing first- and second-order barriers to change: Strategies for technology integration. Educational Technology Research and Development, 47(4), pp. 47-61.

[6] Ertmer, P. (2005). Teacher pedagogical beliefs: The final frontier in our quest for technology integration? Educational technology research and development, 53(4), pp. 25-39.

[7] Niederhauser, D. \& Stoddart, T. (2001). Teachers'instructional perspectives and use of educational software. Teaching and Teacher Education, 17(1), pp. 15-31.

[8] Häkkinen, P. \& Hämäläinen, R. (2012). Shared and Personal Learning Spaces: Challenges for Pedagogical Design. Internet and Higher Education, 15(4), pp. 231-236.

[9] Lehtinen, E. (2006). Teknologian kehitys ja oppimisen utopiat [On the development of technology and utopias of learning] . In Järvelä, P. Häkkinen, \& E. Lehtinen (Eds.), Oppimisen teoria ja teknologian opetuskäyttö [Learning theory and pedagogical use of IT] (pp. 264-278). Porvoo: WSOY.

[10] Looi, C.-K., Seow, P., Zhang, B., So, H.-J., Chen, W., \& Wong, L.-H. (2010). Leveraging mobile technology for sustainable seamless learning: a research agenda. British Journal of Educational Technology, 41(2), pp. 154-169.

[11] Rikala, J., Vesisenaho, M. \& Mylläri, J. (2013). Actual and potential pedagogical use of tablets in schools. Human Technology 9 (2), pp. 113-131.

[12] Kember, D. (1997). A reconceptualisation of the research into university academics' conceptions of teaching. Learning and Instruction, 7 (3), pp. 255-285.

[13] Kember, D. \& Kwan, K. (2000). Lecturers' approaches to teaching and their relationship to conceptions of good teaching. Instructional Science, 28 (5), 469-490.

[14] Wang, R., Dunne \& Rowe, E. (2008). The Exeter Pathfinder Journey. DOI=http://www.heacademy.ac.uk/assets/York/documents/ourwork/learningandtech/completed/ pathfinder/Journey_Reports/Exeter_UPDATED.pdf

[15] Tuomi, J. \& Sarajärvi, A. (2004). Laadullinen tutkimus ja sisällönanalyysi [Qualitative research and content analysis]. Helsinki: Tammi. 